Boise State University

ScholarWorks

\title{
Mitigation of Distribution Voltage Violations Using Single-Phase Residential Static VAr Compensators
}

Andrés Valdepeña Delgado

Boise State University

Muhammad Kamran Latif

Boise State University

Said Ahmed-Zaid

Boise State University 


\title{
Mitigation of Distribution Voltage Violations Using Single-Phase Residential Static VAr Compensators
}

\author{
Andrés Valdepeña Delgado, Muhammad Kamran Latif and Said Ahmed-Zaid \\ Department of Electrical and Computer Engineering \\ Boise State University \\ Boise, Idaho 83725 \\ Email: AndresValdepena@u.boisestate.edu,MuhammadLatif@u.boisestate.edu, sahmedzaid@boisestate.edu
}

\begin{abstract}
An alternative method to support the voltage at the end of a distribution feeder using residential static VAR compensators (RSVCs) is presented. The distribution feeder and the RSVCs were modeled using OpenDSS and validated by comparing the results of measured data with the output of the model. Results show that the use of RSVCs on the low side of the service transformers is an efficient way to mitigate low- and high-voltage violations in the distribution feeder. During a onemonth evaluation of the system, the results show that the use of RSVCs was able to eliminate all voltage violations below $113 \mathrm{~V}$ and it reduced the number of voltage violations under $114 \mathrm{~V}$ by $\mathbf{8 8 \%}$.
\end{abstract}

Keywords-Distribution Feeder, Residential Static VAR Compensator, OpenDSS, Voltage Violation, Mitigation

\section{INTRODUCTION}

Aging infrastructure, exceeding nameplate ratings, and low-voltage violations are some of the reasons utilities invest in asset replacement and upgrade projects. However, upgrading utility assets usually requires a substantial long-term commitment. Therefore, a careful consideration must be given to replacing or upgrading these assets. Distribution systems are going through a structural transformation from being radiallyoperated simple systems to becoming more complex networks to operate in the presence of distribution energy resources (DERs) with significant levels of penetration. The new distribution system needs to optimize conductor sizes, minimize reactive power flow, maintain the voltage within a tight range, and minimize losses. Thus, distribution asset deferral is being considered as an alternative to asset upgrades.

Several ways have been identified for deferring equipment upgrades such as an accurate forecast of load growth, conservation by voltage reduction [1], demand response management [2], distributed generation [3], and battery storage [4], [5]. However, finding cost effective asset deferral strategies has proven difficult because the few options available are either difficult to implement or are still too expensive. Most of the literature focuses on deferring asset replacement driven by an anticipated peak load exceeding the nameplate rating. The range of standard service voltages used in the United States is specified by the American National Standards Institute in ANSI C84.1 2016 "Electrical Power Systems and Equipment - Voltage Ratings (60 Hertz)" as 120 volts nominal, 114 volts minimum (120 V minus 5\%) and 126 volts maximum (120 V plus $5 \%$ ). Therefore, utilities are mandated to provide service voltage within this ANSI range, i.e., between 0.95 per unit and 1.05 per unit. Thus, when the only viable option to mitigate low voltage violations is to upgrade or re-conduct line sections, utilities are forced to invest in very expensive alternatives.

Advancements in power metal-oxide-semiconductor fieldeffect transistors (MOSFETs) and insulated-gate bipolar transistors (IGBTs) have allowed advancements in the development of flexible alternating-current transmission systems (FACTS) devices. One such FACTS device is the Static VAr Compensator (SVC). An SVC is a shunt-connected static var generator or absorber whose output is adjusted to exchange capacitive or inductive current in order to maintain a specific voltage range in electrical transmission systems [6]. SVCs are a well-known technology in the transmission systems of electric power industry but the use of thyristor-based technology, typically in the MVAr size range and non-continuous current conduction, has prohibited their use at the distribution system level. An SVC design was proposed based in theory on the concept of pulse-width modulation (PWM) switching using a bidirectional switching circuit topology [7] with MOSFETs or IGBTs instead of thyristors has enabled a single-phase implementation of an SVC with a reasonable footprint that does not generate substantial low-order harmonics. Recently, a prototype of this single-phase residential static var compensator (RSVC) has proven to operate successfully in a laboratory environment at Boise State University [8] and its application in conservation by voltage reduction has been demonstrated on a distribution feeder in [9].

The paper briefly discusses the technology of RSVCs and presents the results of a study performed on a feeder experiencing a low voltage at the end of a long single-phase branch during a few hours out of the year. The results of this study indicate that RSVCs are able to mitigate the low and high voltages and provide a cost-effective solution by deferring a need of feeder upgrade.

\section{BACKGROUND}

When a customer experiences a low voltage, it could be due to several different factors. A customer experiencing a low voltage at the residential level does not necessarily means the voltage at the distribution feeder head is low. There are multiple cases when the voltage experienced by the customer is low due to problems that exist on the low-voltage side of the distribution system such as a residential transformer overload, small service conductors, motor star-up, etc. Using voltage reads from the advance metering infrastructure (AMI), it is possible to detect areas where a low voltage is experienced by more than one customer. In such a situation, a low voltage 
it is an indication that the feeder section voltage is low and customers could be experiencing voltages outside ANSI C84.1 Range A standard.

Utilities have faced low-voltage issues since their creation in the early 1900's. The mitigation options can be separated into low- and high-investment options. Some of the lowinvestment options include adding inline voltage regulators in long feeders, using a single or multiple capacitor banks in the distribution substation, balancing loads on the primary feeder, transferring loads to new feeders, etc. Some of the highinvestment options include increasing the feeder conductor size, changing the feeder sections from single phase to multiphase, installing new substations and primary feeders, etc.

There exists a wide range of options for controlling the voltage in distribution feeders, from building new facilities to transferring loads from one feeder to another. Rural feeders, in general, experience low load growth and low load density. Any upgrades to the distribution system for mitigating low-voltage issues could be an expensive investment due to the limited options available in rural feeders. The use of service-level solutions by employing residential static var compensator is investigated in this paper as an economical solution to mitigate low and high voltage issues in a rural feeder.

\section{RSVC TECHNOLOGY}

Figure 1 shows a single-phase, PWM-based RSVC circuit. The single-phase RSVC circuit requires two bidirectional switches, each of which is built using two unidirectional switches and two diodes. In the figure, the switches SW1 and SW2 represent two bidirectional switches with complementary gating signals. The switch SW2 is used to conduct the inductor current when switch SW1 is open. By using high-frequency switching, the fundamental component of the inductor current can be controlled [7]. Assuming the switches to be ideal, meaning their switching and conduction losses are negligible, when SW1 is closed (SW2 is open), a voltage $V_{L}$ appears across the inductor. It can be shown that the RMS magnitude of the fundamental component of inductor voltage $V_{L 1, R M S}$ is related to the RMS magnitude of the quasi-sinusoidal input voltage $V_{s, R M S}$ by the following expression,

$$
V_{L 1, R M S}=D V_{s, R M S}
$$

where $D$ is the duty cycle ratio defined as time interval when SW1 is conducting. Similarly, the RMS magnitude of fundamental component of the top switch (SW1) current $I_{S W 1, R M S}$ is related to the RMS magnitude of the quasi-sinusoidal inductor $I_{L 1, R M S}$ current by the following expression,

$$
I_{S W 1, R M S}=D I_{L 1, R M S}
$$

From Equations 1 and 2, the equivalent input inductive reactance $X_{i}$ is continuously variable as a function of the duty cycle $D$ and can be expressed as,

$$
X_{i}(D)=\frac{V_{s, R M S}}{I_{S W, R M S}}=\frac{V_{L 1, R M S} / D}{D I_{L 1, R M S}}=\frac{X_{L}}{D^{2}}
$$

As the duty cycle $D$ increases, the reactive power generated by the inductor compensates the reactive power of the fixed capacitor. Therefore, an RSVC can provide dynamic reactive power compensation at the point of connection to the power system. The output reactive power of the RSVC is the net subtraction of the reactive powers from the capacitor $Q_{C}$ and the PWM-based switched reactor $Q_{L}(D)$ which is expressed as,

$$
Q_{R S V C}=Q_{L}(D)-Q_{C}
$$

Note that $Q_{L}(D)$ is the reactive power of the inductor which is a function of the duty cycle $D$. Therefore, by controlling the duty cycle of the inductor, the net reactive power of the RSVC can be controlled thus allowing the voltage to be regulated at a local service point.

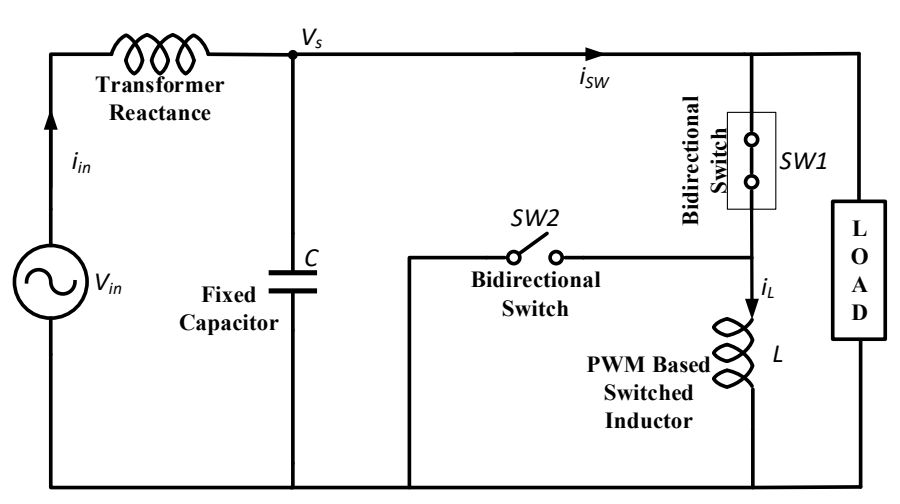

Figure 1: RSVC Circuit with two bidirectional switches

The proposed RSVC has several advantages compared to a conventional thyristor-based static var compensator. It produces a a quasi-sinusoidal inductor current without the lower-order harmonics injected in the power system due to non-sinusoidal inductor current. This improvement enables the realization of the static var compensators as a singlephase devices instead of traditional thyristor-based three-phase devices. The proposed RSVC has a subcycle reactive power controllability. The two switches are turned on and off in a complementary manner using a pulse-width modulation technique at a frequency much greater than that of the supply voltage which allows the reactor to function as a continuouslyvariable inductor. Moreover, the proposed RSVC has a lower footprint for its reactive components as it is targeted for the residential customers in the distribution system.

\section{Power System Case Study}

A study was performed on a rural feeder in Idaho, USA which was experiencing a low voltage at the end of a long single-phase branch during a short period of time in the summer each year. The section of the distribution feeder facing a low voltage problem included a 7.2-kW, 50-A, 32-steps voltage regulator 20 miles away from the substation. The voltage regulator was used to regulate voltages for twelve customers that were served from nine service transformers. During the low voltage, the settings of the voltage regulator were adjusted to boost the voltage level. However, customers near the voltage regulator experienced high voltages. Several traditional voltage quality improvement options were investigated but none of them presented a feasible and cost-effective solution. For example, the area experiencing the low voltage is a long singlephase branch thus eliminating the possibility of balancing loads on the feeder or moving loads to a different feeder. Moreover, 
This is an author-produced, peer-reviewed version of this article. The final, definitive version of this document can be found online at 2019 IEEE 62nd International Midwest Symposium on Circuits and Systems (MWSCAS), published by IEEE. Copyright restrictions may apply. doi: 10.1109/ MWSCAS.2019.8884842

the distribution feeder already had three stages of voltage regulation in place. Adding another voltage regulator could cause serious overvoltages in the event of a trip-close. There was a possibility of upgrading the feeder conductor size or change the feeder section from single-phase to multi-phase, but this latter solution was not deemed economically feasible.

\section{A. Feeder Modelling in OpenDSS}

Figure 2 shows a single-line diagram of the distribution feeder section under consideration. A voltage meter was installed upstream of the voltage regulator to obtain the input voltage at the regulator and a current meter was installed to measure the current flowing downstream. Another voltage meter was installed at the end of the single-phase branch for validating the feeder model developed for simulation.

A detailed feeder model was developed and simulated with all the feeder elements modeled from downstream of the voltage regulator in OpenDSS. The feeder model included the distribution lines conductors, the service transformers and the service line conductors to AMI meters at the customers. The load for each customer was obtained using the energy usage data in one-hour intervals from the electric utility billing department. In order to account for the load variations during each hour, the load allocation was fine tuned after every five minutes using the current sensor readings and the voltages obtained from AMI meters. The model was verified by comparing the voltages recorded at the customers using AMI meters and the voltages obtained from the OpenDSS feeder model.

During the 31-day period of analysis for the month of July in 2016, three customers experienced a voltage higher than that specified by ANSI C84.1 standard and two customers experienced a low voltage. In total, there were a total of 57 minimum voltage violations on different occasions, nine of them were lower than $113 \mathrm{~V}$, with voltage regulators set at maximum voltage setting. Figure 3 shows the voltage at each one of the meters located downstream of the regulator using box plots. In each box, the central line indicates the median data value, and the bottom and top edges of the box indicate the $25^{t h}$ and $75^{t h}$ percentiles, respectively. The whiskers extend to the maximum and minimum data points for each box plot. The outliers in the data are plotted individually using the ' + ' symbol. It can be seen that each customer experienced a wide range of voltage swing several times during the month of July with some of the voltages outside the normal distribution voltage standard. Table I tabulates the maximum, minimum and average voltages for every customer.

\section{B. Mitigation of Voltage Violations using RSVCs}

The effect of adding RSVCs to the system was studied by adding an RSVC to each service transformer located downstream of the voltage regulator as shown in Figure 2. The RSVCs were modelled as generators in OpenDSS with the capacitive and reactive powers set to the prototype developed at Boise State University. The nameplate capacity of a singlephase RSVC was $10 \mathrm{kVAr}$ capacitive $\left(Q_{C}\right)$ and $15 \mathrm{kVAr}$ inductive $\left(Q_{L}\right)$. For the customers that have a service transformer with $480 \mathrm{~V}$ in the secondary side, the RSVC was modelled with approximately twice the capacity as the prototype, i.e.,

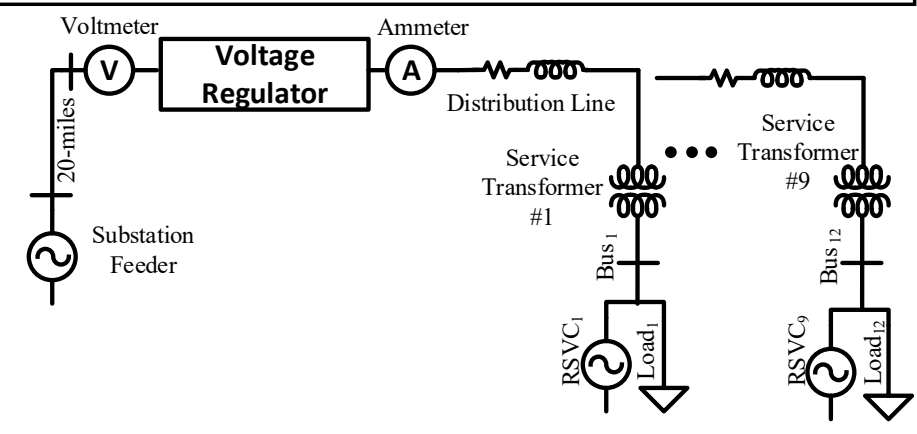

Figure 2: Distribution feeder topology chosen for the study

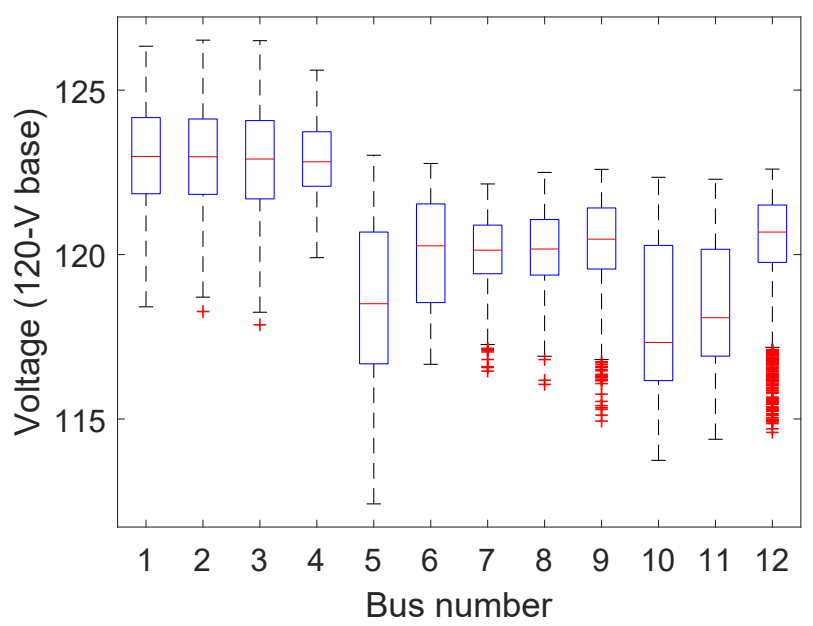

Figure 3: Voltage at every customer meter without RSVC in shunt with the service transformers.

Table I: Voltage swing for each customer without RSVC

\begin{tabular}{|c|c|c|c|}
\hline Bus No. & Minimum Voltage & Maximum Voltage & Average Voltage \\
\hline \hline Bus 1 & 118.41 & 126.33 & 122.90 \\
\hline Bus 2 & 118.27 & 126.52 & 122.87 \\
\hline Bus 3 & 117.86 & 126.50 & 122.78 \\
\hline Bus 4 & 119.91 & 125.61 & 122.83 \\
\hline Bus 5 & 112.42 & 123.02 & 118.46 \\
\hline Bus 6 & 116.66 & 122.77 & 120.02 \\
\hline Bus 7 & 116.46 & 122.15 & 120.09 \\
\hline Bus 8 & 116.05 & 122.50 & 120.10 \\
\hline Bus 9 & 114.93 & 122.59 & 120.23 \\
\hline Bus 10 & 113.74 & 122.35 & 118.00 \\
\hline Bus 11 & 114.38 & 122.29 & 118.43 \\
\hline Bus 12 & 114.59 & 122.60 & 120.13 \\
\hline
\end{tabular}

$20 \mathrm{kVAr}$ in the capacitive mode and $30 \mathrm{kVAr}$ in the inductive mode.

In the simulation, the voltage reference for all of the RSVCs was set at 1.0 per unit on a $120-\mathrm{V}$ voltage base. Figure 5 shows the box plot results after adding an RSVC at each bus in the effected section of the distribution feeder. The results show that voltages were improved at every location of the feeder. In general, adding an static var compensator with the service transformer at the residential level reduced the instances of a low voltage instance to only six, none of which were below $113 \mathrm{~V}$. Moreover, RSVCs also helped in reducing the voltage swing at each bus in the feeder thus 
maintaining a more constant voltage through a month-long simulation. Table II shows that no customers experienced a voltage higher than $126 \mathrm{~V}$ and only one customer experienced a voltage below $114 \mathrm{~V}$.

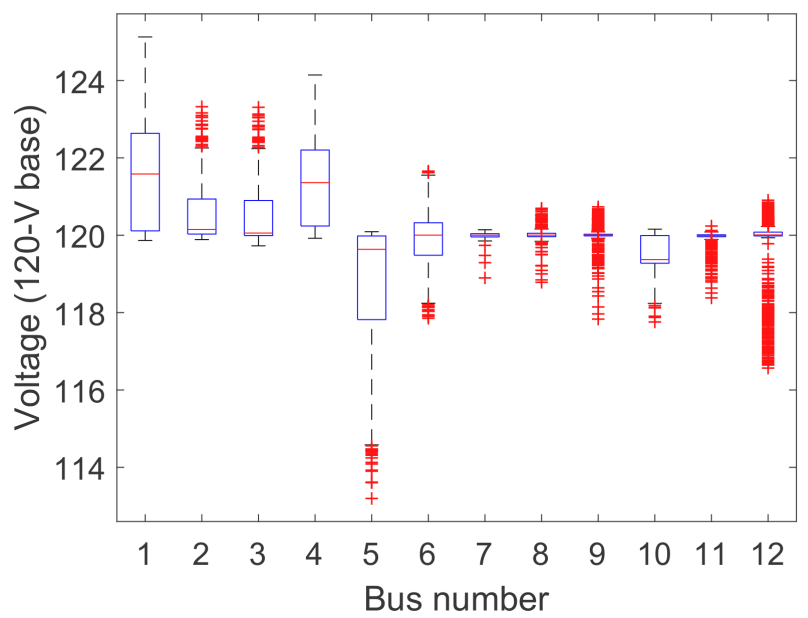

Figure 4: Voltage at every customer meter when the RSVC voltage is set at 1.0 per unit in shunt with the service transformer.

Table II: Voltage swing for each customer with RSVC

\begin{tabular}{|c|c|c|c|}
\hline Bus No. & Minimum Voltage & Maximum Voltage & Average Voltage \\
\hline \hline Bus 1 & 119.86 & 125.13 & 121.56 \\
\hline Bus 2 & 119.89 & 123.32 & 120.53 \\
\hline Bus 3 & 119.73 & 123.31 & 120.46 \\
\hline Bus 4 & 119.92 & 123.31 & 121.35 \\
\hline Bus 5 & 113.20 & 120.09 & 118.70 \\
\hline Bus 6 & 117.85 & 121.66 & 119.90 \\
\hline Bus 7 & 118.90 & 120.14 & 120.00 \\
\hline Bus 8 & 118.78 & 120.70 & 120.01 \\
\hline Bus 9 & 117.83 & 120.73 & 119.99 \\
\hline Bus 10 & 117.76 & 120.16 & 119.52 \\
\hline Bus 11 & 118.38 & 120.24 & 119.94 \\
\hline Bus 12 & 116.57 & 120.71 & 119.71 \\
\hline
\end{tabular}

The reactive power output of the RSVCs at each bus is shown in Figure 5. Each point in the figure shows the net reactive power provided by the RSVC for a five-minute interval at a specific service transformer during the entire month of July in 2016. The result shows that RSVCs can transition from an inductive operation mode to a capacitive operating mode thus providing a better voltage regulation profile than with capacitors alone.

\section{Conclusions}

This paper focused on a novel single-phase static var compensator technology that is suited for handling voltage quality problems at the residential level. The analysis performed in this study indicates that distribution voltage violations outside the ANSI C84.1 Range A can be mitigated by deploying RSVCs at load points with the worst regulation. The model of the feeder section under investigation was developed in detail in OpenDSS and field verified for accuracy purposes. The simulation results show that it is possible to mitigate lowas well as high-voltage issues in a rural distribution feeder

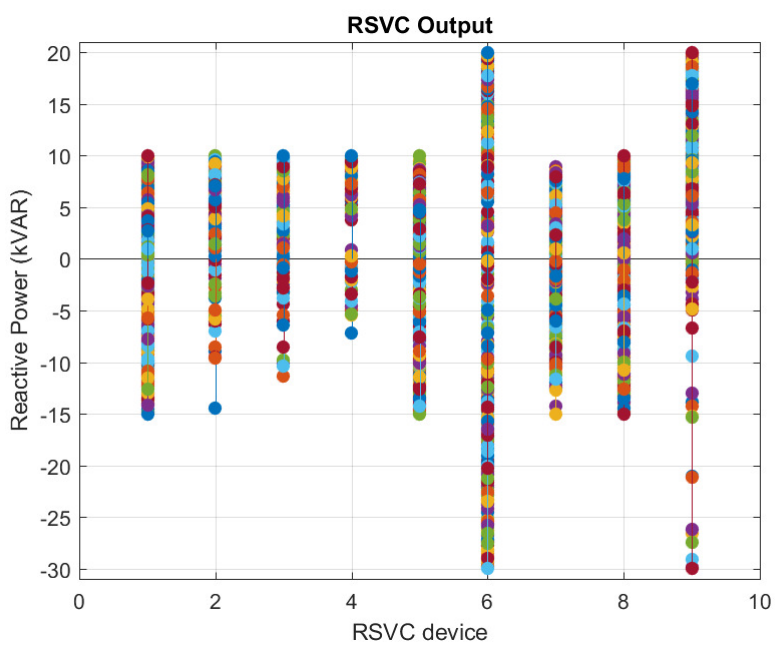

Figure 5: Reactive power for RSVC at every meter when voltage is set at 1.0 per-unit

by using RSVCs without upgrading the feeder. Thus, the use of RSVCs could be a more economical solution to resolve voltage issues in distribution feeders. It was also observed that the voltage swing at each RSVC installation was greatly reduced, thus creating a flatter voltage profile and increasing the flexibility to operate the feeder at a higher or lower voltage level at the feeder head.

\section{ACKNOWLEDGMENT}

The authors would like to thank Mr. Randy Gnaedinger and Avista Utilities for their support of the RSVC project.

\section{REFERENCES}

[1] J. C. Erickson and S. R. Gilligan, "The effects of voltage reduction on distribution circuit loads," IEEE Transactions on Power Apparatus and Systems, vol. PAS-101, no. 7, pp. 2014-2018, July 1982.

[2] V. Stanojevic, M. Bilton, J. Dragovic, J. Schofield, and G. Strbac, "Application of demand side response and energy storage to enhance the utilization of the existing distribution network capacity," in 22nd International Conference and Exhibition on Electricity Distribution (CIRED 2013), June 2013

[3] X. Li and G. K. Zielke, "One-year deferral method for estimating avoided transmission and distribution costs," IEEE Transactions on Power Systems, vol. 20, no. 3, pp. 1408-1413, Aug 2005.

[4] J. Ever and G. Corey, "Energy storage for the electricity grid: Benefits and market potential assessment guide," Albuquerque, NM, Tech. Rep., 2010.

[5] J. M. G. Fitzgerald and H. Touati, "The economics of battery energy storage," Boulder, CO, Tech. Rep., 2015.

[6] J. Dixon, L. Moran, J. Rodriguez, and R. Domke, "Reactive power compensation technologies: State-of-the-art review," Proceedings of the IEEE, vol. 93, no. 12, pp. 2144-2164, Dec 2005.

[7] H. Jin, G. Goos, and L. Lopes, "An efficient switched-reactor-based static var compensator," IEEE Transactions on Industry Applications, vol. 30, no. 4, pp. 998-1005, Jul/Aug 1994.

[8] M. K. Latif, "Hardware realization of a residential static var compensator," Master's thesis, Boise State University, Boise State University Theses and Dissertations, 2017.

[9] J. Stubban, S. Ahmed-Zaid, and M. K. Latif, "Conservation by voltage reduction using a single-phase residential static var compensator," in 2018 Clemson University Power Systems Conference (PSC), Sept 2018. 